\title{
Isolation and Fractionation of an Extracellular Polysaccharide from Marine Vibrio
}

\author{
Koichi OKuTani* \\ (Accepted August 2, 1984)
}

\begin{abstract}
Vibrio sp. M-812 strain, isolated from marine sediment, produced an extracellular acidic polysaccharide when grown on sea water media containing sucrose. The crude polysaccharide preparation contains residues of rhamnose, galactose, glucose and uronic acid, and protein moiety.

The crude polysaccharide preparation was separated into two fractions, a high molecular weight and a low molecular weight polymer, by chromatography on Sepharose 4B. A high molecular weight polysaccharide preparation was rechromatographed on Sepharose 2B and gave two peaks. These polymers fractionated by gel chromatography were heterogeneous in electrophoresis on cellulose acetate strips.
\end{abstract}

In the course of screening for biologically active polysaccharide produced by marine organisms, ${ }^{1-12)}$ the present author isolated a polysaccharide-producing bacterium from the marine sediment.

Extraction and separation procedures for obtaining this bacterial extracellular polysaccharide are reported, as are qualitative and quantitative chemical analyses.

\section{Materials and Methods}

\section{General Methods}

Ultracentrifugal analyses were performed with a Hitachi 282 analytical ultracentrifuge. Sedimentation patterns were made on $0.1 \mathrm{M}-\mathrm{NaCl}$ solution. Sedimentation patterns were obtained at various times after the rotor had reached at maximum speed of $60,000 \mathrm{rpm}$ at $25^{\circ} \mathrm{C}$. Electrophoresis were performed on cellulose acetate strips (Sartorius $11200,57 \times 145 \mathrm{~mm}$ ) in $0.075 \mathrm{M}$ barium acetate solution at $200 \mathrm{~V}$ for $15 \mathrm{~min}$, and then developed in Alcian Blue.

The free acid form (H-form) of the polysaccharide was obtained by passing a solution of the native polysaccharide ( $\mathrm{Na}$-form) through a column of Amberlite IR-120( $\left.\mathrm{H}^{+}\right)$resin, followed by dialysis and freeze-drying.

Analyses of the monosaccharide constituents were carried out by paper chromatography and gas liquid chromatography (GLC) after hydrolysis. Paper chromatography was conducted on Whatman No. 1 paper by the descending method and in $18: 3: 1: 4$ of ethyl acetate-acetic acid-formic acid-water as the solvent (V/V). Chromatograms were developed by using the alkaline silver nitrate and aniline hydrogen phthalate reagents. The alditol acetates were analyzed by GLC on glass columns $(0.3 \times 200 \mathrm{~cm})$ using a Hitachi $263-30$ instrument equipped with dual flame ionization detectors using nitrogen as the carrier gas at a flow rate of $15 \mathrm{~m} / / \mathrm{min}$. The columns used were (1) $3 \%$ of SP-2340 on Uniport HP (100-120 mesh), and (2) $3 \%$ of OV-225 on Uniport HP (80-100 mesh), programmed from $190^{\circ} \mathrm{C}$ for $4 \mathrm{~min}$ and then at $4^{\circ} \mathrm{C} / \mathrm{min}$ to $250^{\circ} \mathrm{C}$. Identification of sugar residues was achieved by cochromatography with authentic standards.

Gel-filtration chromatography was performed using Sepharose $2 \mathrm{~B}$ and $4 \mathrm{~B}$ columns equilibrated in $0.1 \mathrm{M}-\mathrm{NaCl}$ solution. Blue dextran 2000 (Pharmacia) and glucose were run on the columns to determine the void volume $\left(\mathrm{V}_{0}\right)$ and included volume $\left(V_{1}\right)$, respectively. The sample was applied to a column and eluted with $0.1 \mathrm{M}-\mathrm{NaCl}$. Fractions were collected and analyzed for sugar content by means of the phenol-sulfuric acid reagent. ${ }^{13)}$ All fractions were also determined for UV light absorption at $280 \mathrm{~nm}$. Uronic acid content of the polysaccharide was estimated by the carbazol method ${ }^{14)}$ with glucuronic acid as the standard. Protein determinations were done by the LownY method ${ }^{15)}$ with egg albumin as the standard. Amino sugar analysis was performed with a modification of ELSON-MORGAN procedure $^{18)}$ with glucosamine- $\mathrm{HCl}$ as the standard.

\section{Preparation of the Polysaccharide}

A culture of Vibrio sp. M-812 strain was in the

\footnotetext{
* Faculty of Agriculture, Kagawa University, Kagawa 761-07, Japan (奥谷㢃一: 香川大学農学部).
} 
collection of this laboratory, which was originally isolated in the surface layer of the marine sediments. ${ }^{12)}$ Three day's old culture on agar medium was seeded to a test tube containing $10 \mathrm{~m} l$ of the sea water broth having the following composition per liter of sea water; Sucrose $(30 \mathrm{~g})$, Peptone $(5 \mathrm{~g})$, Yeast extract $(1 \mathrm{~g})$. The culture was incubated for 3 days at $25^{\circ} \mathrm{C}$ and distributed to 250 $\mathrm{ml}$ of agar plate $(18 \times 26 \mathrm{~cm})$ having the same medium supplemented with agar $(1.5 \%)$. These were incubated under the same conditions. The viscous materials containing bacterial cells were harvested, and diluted with water containing $1 \%$ of phenol. This suspension was then centrifuged for $1 \mathrm{~h}$ at $30,000 \mathrm{rpm}$ with a Hitachi $55 \mathrm{P}-72 \mathrm{ul}-$ tracentrifuge fitted with rotor type RP42. The clear but somewhat opalescent supernatant liquor was separated, and the polysaccharide was precipitated with 3 vol. of ethanol. The precipitate isolated by centrifugation was dissolved in water, and then precipitated with $5 \%$ Cetavlon (Cetyltrimethylammonium bromide) solution. The precipitate was isolated by centrifugation, and dissolved in $2 \mathrm{M}-\mathrm{NaCl}$ solution. The polysaccharide was reprecipitated with 3 vol. of ethanol. This polysaccharide was isolated by centrifugation, dissolved in water, and then dialyzed for 3 days against running water. Freeze-drying of this solution yielded $700 \mathrm{mg}$ of the polysaccharide per $1 l$ of the medium.

This polysaccharide preparation was treated again by precipitation with ethanol and Cetavlon. The final polysaccharide preparation yielded 470 mg per $1 l$ of the medium (Crude polysaccharide preparation).

\section{Sugar Analysis}

The polysaccharide $(20 \mathrm{mg})$ was hydrolyzed with $10 \mathrm{ml}$ of $2 \mathrm{M}$-trifluoroacetic acid (TFA) overnight at $100^{\circ} \mathrm{C}$. The acid was removed by several evaporations with water under the diminished pressure. The sugar released was identified by paper chromatography and GLC. On GLC analysis, a portion of the hydrolyzate was reduced with sodium borohydride and the mixture was treated with Amberlite IR-120( $\left.\mathrm{H}^{+}\right)$cation exchange resion and filtered. The filtrate was evaporated three times with methanol in order to remove borate ion. The product was acetylated with acetic anhydride-pyridine (1:1). The alditol acetates of sugar were analyzed by GLC. Total sugar analyses were performed by methanolysis. Methanolysis of a sample $(20 \mathrm{mg})$ with $5 \%$ methanolic hydrogen chloride overnight at $100^{\circ} \mathrm{C}$ and neutralization with silver carbonate, and subsequent treatment with sodium borohydride in anhydrous methanol reduced the uronic acid residues in the polysaccharide. Carboxyl reduced sugars were further hydrolyzed with 2 M-TFA overnight at $100^{\circ} \mathrm{C}$. The sugar released was derivatized to alditol acetate and identified by GLC.

\section{Results and Discussion}

Fractionation of the Crude Polysaccharide Preparation

The crude polysaccharide preparation gave heterogeneous peaks in ultracentrifugal analysis (Fig. 1), and heterogeneous bands in electrophoresis on cellulose acetate strips. Heterogeneity
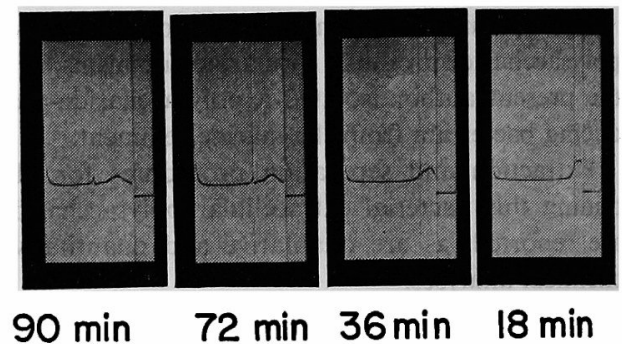

Fig. 1. Ultracentrifugal patterns for the crude polysaccharide preparation.

The sample was dissolved in $0.1 \mathrm{M}-\mathrm{NaCl}$ solution $(40 \mathrm{mg} / 4 \mathrm{ml})$. Sedimentation is from right to left.

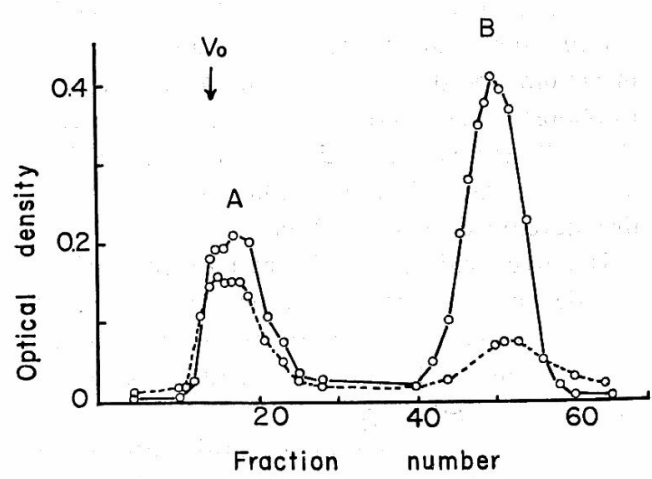

Fig. 2. Chromatography of the crude polysaccharide on Sepharose 4B.

The sample $(50 \mathrm{mg})$ was applied to a column $(2.2 \times 78 \mathrm{~cm})$ and eluted with $0.1 \mathrm{M}-\mathrm{NaCl}$ solution at a flow rate of $8.8 \mathrm{~m} l / \mathrm{h}$. Fractions $(4.4 \mathrm{ml})$ were analyzed for sugar $(-)$ and ultraviolet absorption at $280 \mathrm{~nm}(--)$. 


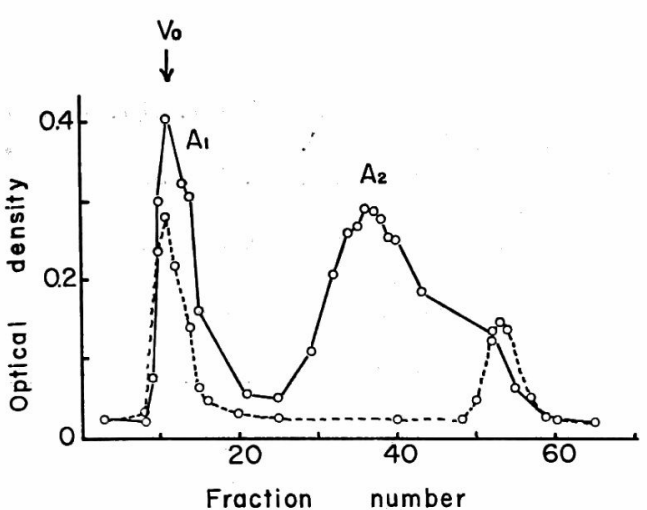

Fig. 3. Chromatography of the Polymer A on Sepharose 2B.

The sample $(25 \mathrm{mg})$ was applied to a column $(2.2 \times 85 \mathrm{~cm})$ and eluted with $0.1 \mathrm{M}-\mathrm{NaCl}$ solution at a flow rate of $7.8 \mathrm{~m} / / \mathrm{h}$. Fractions $(3.9 \mathrm{~m} l)$ were analyzed for sugar (-) and ultraviolet $a b$ sorption at $280 \mathrm{~nm}(---)$.

of this material was also observed by gel chromatography (Fig. 2).

As shown in Fig. 2, two peaks (A and B) were seen on a column of Sepharose 4B. The fractions comprising each peak were pooled and dialyzed against water for 3 days and converted to the free acid form using Amberlite IR-120 $\left(\mathrm{H}^{+}\right)$resin, and freeze-dried (Polymer A and B). Yields of the polymers fractionated by this method were $22.8 \%$ for the Polymer A and $40.0 \%$ for the Polymer B (Calculated from the crude polysaccharide preparation). The Polymer A seemed to contain at least two polysaccharides in gel chromatography on Sepharose 4B (Fig. 2). It was rechromatographed on a column of Sepharose 2B (Fig. 3). Two peaks $\left(A_{1}\right.$ and $A_{2}$ ) were observed, one high molecular weight and another low molecular weight polysaccharide, when the fractions were monitored for sugar. The Polymer $\mathrm{A}_{1}$ is excluded by the gel chromatography on Sepharose $2 B$, indicating that the polymer may have a very high molecular weight. Yields of the polymers fractionated by this method were $46 \%$ for the Polymer $A_{1}$ and $52 \%$ for the Polymer $A_{2}$ (Calculated from the Polymer A). Heterogeneity of the Polymer A was also observed by ultracentrifugal analysis (Fig. 4) and electrophoresis.

On submitting the crude polysaccharide to gel fractionation on Sepharose 4B, major component of the polysaccharide, Polymer B, accounting approximately $40 \%$ of the sample was isolated as a low molecular weight polymer (Fig. 2). Ultracentri-
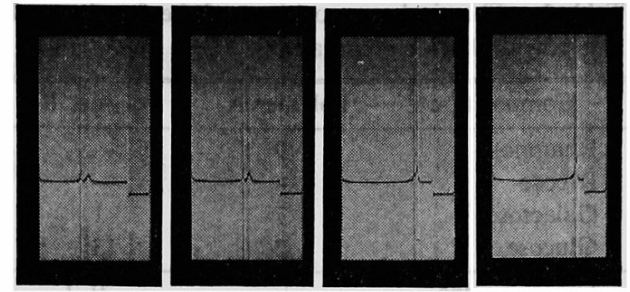

\section{$90 \mathrm{~min} 72 \mathrm{~min} 36 \mathrm{~min} 18 \mathrm{~min}$}

Fig. 4. Ultracentrifugal patterns for the Polymer A. The sample was dissolved in $0.1 \mathrm{M}-\mathrm{NaCl}$ solution $(40 \mathrm{mg} / 6 \mathrm{ml})$. Sedimentation is from right to left.
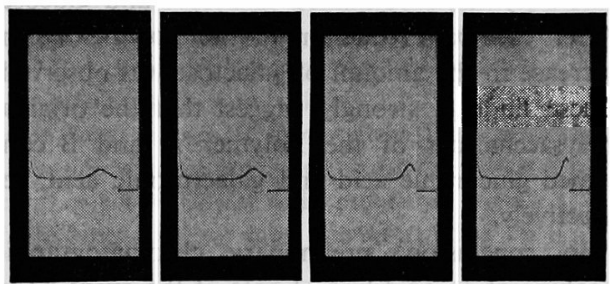

$90 \min$

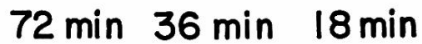

Fig. 5. Ultracentrifugal patterns for the Polymer B.

The sample was dissolved in $0.1 \mathrm{M}-\mathrm{NaCl}$ solution $(40 \mathrm{mg} / 4 \mathrm{ml})$. Sedimentation is from right to left.

fugal analysis of the Polymer B indicated the homogeneity of this polysaccharide preparation (Fig. 5). However, this polysaccharide preparation gave two bands in electrophoresis on cellulose acetate strips. Although this material elutes as a single peak off of molecular sieve column, there is a possibility that more than one component exists in this preparation.

\section{Chemical Analyses of the Polysaccharide Pre- parations}

The UV spectra of solutions of the Polymer A and B did not have a maximum at $260 \mathrm{~nm}$. Moreover, in subsequent investigations of the crude polysaccharide preparations by paper chromatography and by GLC, no ribose was detected to substantiate the presence of nucleic acid.

The crude polysaccharide contained rhamnose, galactose, glucose and uronic acid, and protein. The sugars and protein found in the Polymer A and B are listed in Table 1. The Polymer A contained rhamnose, galactose and glucose. After carboxyl reduction of the Polymer A polysaccharide, an increase in the amount of glucose was observed. 
Table 1. Chemical compositions of the fractionated polysaccharide preparations

\begin{tabular}{lcc}
\hline \multicolumn{1}{c}{ Composition* } & Polymer A & Polymer B \\
\hline Rhamnose & 9 & - \\
Ribose & - & - \\
Galactose & 7 & 1 \\
Glucose & 2 & 13 \\
\hline Uronic acid** & + & 9.2 \\
Protein** & + & 4.0 \\
Amino sugar** & - & - \\
\hline$+:$ Present but not quantitative. & \\
$-:$ Not observed. & \\
*: Expressed by molar ratios. & \\
**: Expressed as percent of the sample &
\end{tabular}

The Polymer B contained galactose and glucose. After carboxyl reduction of the Polymer B, an increase in the amount of galactose was observed. These findings strongly suggest that the original polysaccharides of the Polymer $\mathbf{A}$ and $\mathbf{B}$ contained glucuronic acid and galacturonic acid, respectively.

In conclusion, preliminary chromatographic analysis of an acid hydrolyzate of the crude polysaccharide preparation produced by marine Vibrio sp. M-812 strain revealed the presence of rhamnose, galactose, glucose and uronic acid, in addition to protein moiety. Although attempts to obtain pure sample were unsuccessful, this polysaccharide preparation was separated into three fractions by chromatographies on Sepharose $2 B$ and $4 B$.

This investigation is being continued.

\section{References}

1) K. OKutani: Tech. Bull. Fac. Agr. Kagawa Univ., 26, 75-78 (1974).

2) K. OKutani: Bull. Japan. Soc. Sci. Fish., 42, 367-370 (1976).

3) K. Okutani: Bull. Japan. Soc. Sci. Fish., 42 449-453 (1976).

4) K. Okutani: Bull. Japan. Soc. Sci. Fish, 42, 1373-1379 (1976).

5) K. Oxutani: Bull. Japan. Soc. Sci. Fish., 43, 323-328 (1977).

6) OKutani and N. Morikawa: Bull. Japan. Soc. Sci. Fish., 44, 369-372 (1978).

7) K. OKutani and N. MorikaWa: Bull. Japan. Soc. Sci. Fish., 54, 749-753 (1978).

8) K. Okutani: Bull. Japan. Soc. Sci. Fish., 48, 421-424 (1982).

9) K. Okutani: Bull. Japan. Soc. Sci. Fish., 48, 1621-1625 (1982).

10) K. Okutani: Bull. Japan. Soc. Sci. Fish., 50, 1035-1037 (1984).

11) K. Okutani: Bull. Japan. Soc. Sci. Fish., 50, 1407-1412 (1984).

12) K. Okutani: Tech. Bull. Fac. Agr. Kagawa Univ., 36, 47-51 (1984).

13) M. Dubois, K. A. Gilles, J. K. Hamilton, P. A. Rebers, and F. Smith: Anal. Chem., 28, 350356 (1956).

14) Z. DiSCHE: J. Biol. Chem., 167, 189-198 (1947).

15) O. H. Lowry, N. J. Rosebrough, A. L. FarR, and R. J. Randall: J. Biol. Chem., 193, 265275 (1951).

16) C. J. M. Rondle and W. T. J. MORgan: Biochem. J., 61, 586-589 (1955). 